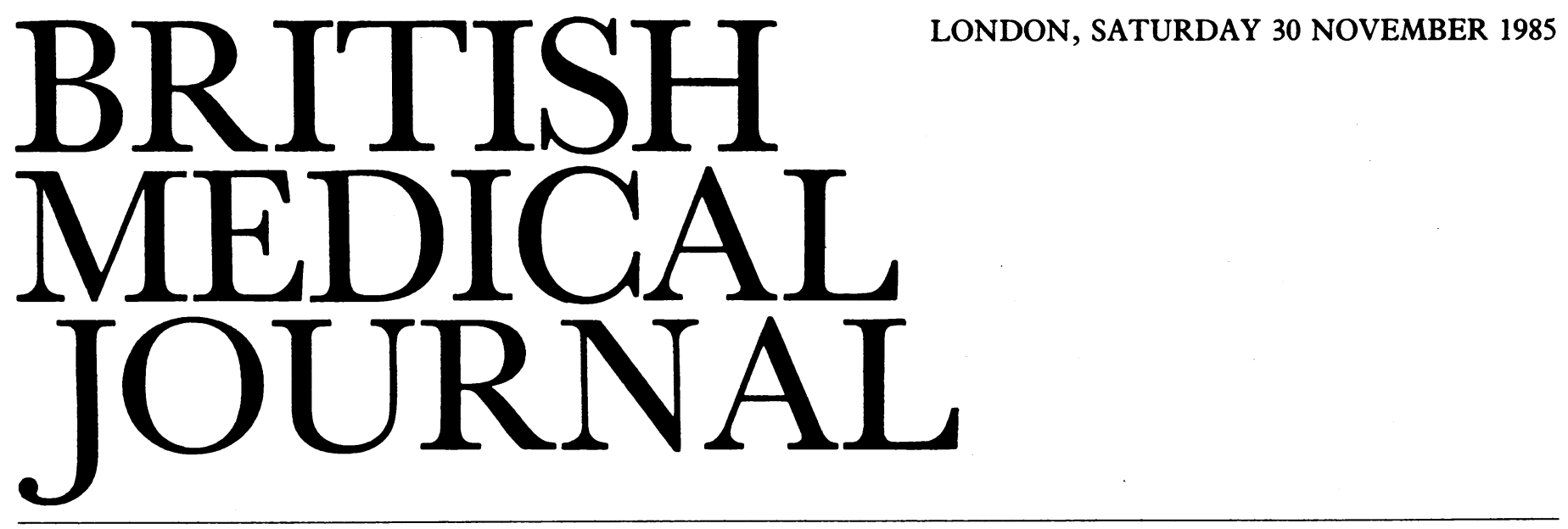

\title{
Women and mental illness
}

One of the more consistent findings of epidemiological research is that women report symptoms of both physical and mental illness and consult doctors for these conditions at higher rates than men. ${ }^{1}$ That finding stands in sharp contrast to the longer female life expectancy than that of males at every age. The explanation most often offered for this sex difference refers to strains and stresses associated with woman's biological state. From such a biological perspective women have been seen as the products and prisoners of their reproductive systems. ${ }^{2}$ Such a view was held with particular vigour by nineteenth century physicians; as one explained in 1827 (in terms not unheard today), the female sex "is far more sensitive and susceptible than the male and extremely liable to those distressing affections which for want of some better term have been determined nervous, and which consist chiefly in painful affections of the head, heart, side, and indeed of almost every part of the system." 3

Contemporary epidemiological research has looked closely at sex differences in depression and in particular those nonpsychotic, mixed anxiety depressive disorders commonly coexisting with social difficulties which are said to affect up to one fifth of the general population. ${ }^{45}$ Sex differences in the prevalence of minor psychiatric morbidity have been shown in many community surveys ${ }^{6.8}$ but a female preponderance has not been invariable. ${ }^{9 \cdot 11}$ Attempts to establish a biological explanation for women's higher rates have not been particularly successful. Recent reviews of the evidence of X linkage and for autosomal linkage with sex related liability thresholds conclude that neither hypothesis can account for the generally observed excess of female vulnerability to affective disorders. ${ }^{12}$ Indeed, genetic factors are of negligible importance in most neurotic illnesses. ${ }^{13}$ Although depression is known to be more frequent in the postpartum period the evidence that hormones have a causal role is, as yet, only circumstantial. $^{1+17}$ And contrary to widely held views the menopause has no effect on rates of depression. ${ }^{18}$ Premenstrual tension and the use of oral contraceptives may, indeed, exercise an effect on depression rates, but this appears to be of small magnitude. ${ }^{19}$ No study has yet succeeded in definitely correlating clinical mental states in men or women with concentrations of gonadal hormones.

Despite these generally negative findings the explanation that women are biologically vulnerable in some way dies hard. Yet the sex differences concerned may well have quite a different cause. Any discussions of the rates should take account of the samples of men and women being rarely homogeneous; they tend to differ in important social vari- ables such as occupation, education, and income. There are obvious methodological advantages to be gained from studying a homogeneous sample, for if social variables are controlled or reduced and no sex difference in mood disorders is then found the possibility that remains is that those social factors account for the sex differences reported in other studies.

One of the few studies which attempted to do precisely this found a very much higher prevalence of anxiety, tension, and other mood disorders in women employed by the New York Telephone Company compared with men..$^{20}$ No account was given, however, of the sex differences of people's grades within the company hierarchy. Similarly, no account was given of the sex distribution within the two groups studied, but telephone operators were mostly women and the craftsmen mostly men. Thus the population was almost certainly not homogeneous for occupation or status. In addition, the residual population studied consisted of $90 \%$ of the men who had been continuously employed by the company over 20 years of follow up but only $10 \%$ of the women, presumably because most women married and left to raise a family. The sample of women studied contained, therefore, a disproportion of the single, widowed, and the divorced, who are often reported to have higher rates of illness than the married. ${ }^{21}$

Most studies of homogeneous populations have been of students, and in general they have failed to show sex differences in rates of depression. Parker reported a study of 242 students undertaking the one year postgraduate diploma of education at an Australian teachers' college. ${ }^{22}$ The sexes were equally represented, and the response rate was high. No sex difference was found on the measures of depression, self esteem, duration of episodes, or frequency of depressive episodes. This study provided support for the findings of two others on comparable groups. S Golin and M A Hartz gave the Beck depression inventory to 446 college students and found that a quarter of both the men and the women scored as depressed (unpublished findings from the University of Pittsburg). Hammen and Padesky also gave the Beck inventory to 2272 college students enrolled at introductory psychology courses and found no sex differences in reporting depression. ${ }^{23}$

The need to seek and study homogeneous groups older than university students led Jenkins to select a sample of relatively homogeneous employed men and women drawn from a population of executive officers in the British Home Office. ${ }^{24}$ The study made careful assessments using the general health questionnaire, ${ }^{25}$ the clinical interview sche- 
dule, ${ }^{26}$ the social stress and supports interview, ${ }^{27}$ and an assessment of various attitudes to work and of work satisfaction. No sex difference was found in the prevalence or outcome of minor psychiatric morbidity in such a homogeneous employed population. This finding supports the view that where sex differences in minor psychiatric morbidity are commonly found they are unlikely to be caused by constitutional differences but rather by differences in the social environment and social roles of men and women.

It could be argued, however, that this study was performed on a relatively childless population and that it is the experience of rearing children which exposes women's greater biological vulnerability to depression. Rosenfield studied the mental health of men and women rearing children and found that the men were more depressed than the women-not supporting the notion that rearing children exposes a greater biological vulnerability to depression in women than men. ${ }^{28}$

Social stresses and supports are implicated in the aetiology of minor psychiatric morbidity, but specific attempts to perform comparative studies between men and women are few. In general women seem not to experience more life events than men, ${ }^{29}$ though women may experience more events of an undesirable nature than men by virtue of their lower socioeconomic state overall. ${ }^{30}$ Women are also more exposed than men to low education, low income, low occupational status, and fewer leisure activities. ${ }^{31}$ Women have less status and frequently earn less than men even when in comparable jobs. ${ }^{32} 33$

"Women are not healthy" wrote Emily Davies in 1866. "It is a rare thing to meet a lady of any age who does not suffer from headaches, languor, hysteria or some other ailment showing a want of stamina." ${ }^{34}$ Miss Davies saw the answer to such invalidism in higher education, although many medical men of the time saw the root cause embedded in what they believed to be the remorseless biological demands placed by nature on womanhood. ${ }^{35}$ Today, the argument continues. $^{243637}$

In view of the substantial genetic evidence that the excess of depression in women is environmental in origin rather than genetic; in view of the paucity of any direct endocrinological evidence linking mood change in men and women with gonadal hormones; in view of the evidence from homogeneous surveys that, when social variables are controlled and reduced, the sex difference disappears; and in the light of the nineteenth century experience, all claims that the excess of depression in women is explained by their reproductive biology —or indeed by their constitution in general - should be treated with grave caution.

RACHEL JENKiNS Consultant in psychological medicine ANTHONY W ClARE

St Bartholomew's Hospital Professor in psychological medicine

London EC1A 7BE

\footnotetext{
Nathanson CA. Sex, illness and medical care: a review of data, theory and method. Soc Sci Med 1977;11:13-25.

2 Smith-Rosenberg $C$, Rosenberg $C$. The female animal: medical and biological views of woman and her role in 19th century. American fournal of Medical History 1973;60:332-56.

3 Hall M. Commentaries on some of the views imparted of the diseases of females. London: Longman, 1827 .

4 Goldberg DP, Huxley P. Mental illness in the community. The pathway to psychiatric care. London Tavistock, 1980

5 Mann AH, Jenkins R, Belsey E. The twelve month outcome of patients with neurotic illness in general practice. Psychol Med 1981;11:535-50.

6 Goldberg DP, Kay C, Thompson L. Psychiatric morbidity in general practice and the community. Psychol Med 1976;6:565-9.

7 Bebbington P, Hurry J, Tennant C, Stoot E, Wing JK. Epidemiology of mental disorders in Camberwell. Psychol Med 1981;11:561-79.

8 Henderson S, Byrne DG, Duncan-Jones P. Neurosis and the social environment. New York: Academic Press, 1981

9 Cornstock GW, Helsing KJ. Symptoms of depression in two communities. Psychol Med $1976 ; 6: 551-63$
}

10 Linn MW, Hunter KI, Perry PR. Differences by sex and ethnicity in the psychosocial adjustment of the elderly. I Health Soc Behav 1979;20:273-81.

11 Dube KC, Kumar N. An epidemiological study of manic depressive psychosis. Acta Psychiatr Scand 1973;49:691-7.

12 Gershon ES, Bunney WE. The question of X-linkage in bipolar manic depressive illness. $\mathcal{f}$ Psychiatr Res 1976;13:99-117.

13 Torgersen $\mathrm{S}$. Genetics of neuroses: the effects of sampling variation upon the twin concordance ratio. Brf Psychiatry 1983;142:126-32.

14 Nott PM, Franklin M, Armitage C, Gelder MG. Hormonal changes in the peurperium. $\mathrm{Br} \mathcal{F}$ Psychiatry 1976;128:379-83.

15 Ballinger CB, Buckley DE, Naylor GJ, Stansfield DA. Emotional disturbances following hildbirth: clinical findings and urinary excretion of cyclic AMP. Psychol Med 1979;9:293-300. 16 Handley SL, Dunn TL, Waldron G, Baker JM. Tryptophan, cortisol and puerperal mood. $\mathrm{Br} \mathcal{F}$ Psychiatry 1980;136:498-508.

17 Kendell RE, Rennie E, Clarke JA, Dean C. The social and obstetric correlates of psychiatric admissions in the puerperium. Psychol Med 1981;11:341-50.

18 Green JG, Cooke DJ. Life stress and symptoms at the climacterium. Br $\mathcal{F}$ Psychiatry 1980;136: 486-91.

19 Clare AW. Psychological and social aspects of premenstrual complaint. Cambridge: Cambridge University Press, 1983. (Psychol Med monogr suppl 4.)

20 Hinkle LE, Redmont R, Plummer N, Wolff HG. An examination of the relationship between symptoms, disability and serious illness in two homogeneous groups of men and women. Am $\mathcal{f}$ Public Health 1960;50:1327-36.

21 Pearlin LI, Johnson JS. Marital status, life strains and depression. Am Sociol Rev 1977;42:704-15. 22 Parker G. Sex differences in non-clinical depression. Review and asse sment of previous studies. Aust NZ J Psychiatry 1979;13:127-32.

23 Hammen CL, Padesky CA. Sex differences in the expression of depressive responses on the Beck Depression Inventory. $\mathcal{F}$ Abnorm Psychol 1977;86:609-14

24 Jenkins R. Sex differences in minor psychiatric morbidity. Cambridge: Cambridge University Press, 1985. (Psychol Med monogr suppl 7.)

25 Goldberg DP. The detection of psychiatric stress by questionnaire. London: Oxford University Press, 1972. (Maudsley Monograph, No 21 .)

26 Goldberg DP, Cooper B, Eastwood M, Kedward HB, Shephard M. A standardised psychiatric interview for use in community surveys. British fournal of Preventive and Social Medicine 1970;24:18-23.

27 Jenkins R, Mann AH, Belsey E. Design and use of a short interview to assess social stress and support in research and clinical settings. Soc Sci Med 1981;15E: 195-203.

28 Rosenfield S. Sex differences in depression: do women always have higher rates? f Health Soc Behav 1980;21:33-42.

29 Dekker DJ, Webb JT. Relationships of the social readjustment rating scale to psychiatric patient status, anxiety and social desirability. I Psychosom Res 1974;18:125-30.

30 Myers JK, Lindenthall JJ, Pepper MP. Life events, social integration and psychiatric symptomatology. F Health Soc Behav 1975;16:421-7.

31 Radloff LS, Rae DS. Susceptibility and precipitating factors in depression; sex differences and similarities. F Abnorm Psychol 1979;88: 174-81.

32 Office of Population Censuses and Surveys. General household survey. London: HMSO, 1980 (Series GHS, No 8 .)

33 Goldstein MZ, Broner EJ, Hanusa BH, Lasell RL. An assessment of backgrounds, training and career experiences of male and female psychiatrists in an American state. Am $\mathcal{f}$ Psychiatry 1981;138:919-24

34 Stephens B. Emily Stephens and Girton College. London: Constable, 1927.

35 Haller IS, Haller RM. The physician and sexuality in Victorian times. New York: Norton and Co, 1974.

36 Jenkins R. Women and minor psychiatric morbidity. $\mathcal{I} R$ Soc Med 1985;78:95-7.

37 Clare AW. Sex and mood. Health and Hygiene 1985;6:43-60.

\section{Massive bladder haemorrhage}

Massive, recurrent bladder haemorrhage is a common complication of current treatments for cancer. It occurs in $10 \%$ of patients given irradiation for pelvic malignancy ${ }^{1}$ and in up to $40 \%$ given cyclophosphamide, ${ }^{23}$ where the bleeding may be further exacerbated by bone marrow depression. Similar massive bleeding may also be seen in patients with urothelial tumours, severe injuries of the bladder, or primary amyloidosis of the bladder..$^{45}$

Recent reports have suggested that a simple, safe remedy for bleeding after irradiation may be alum solution as a bladder irrigation. ${ }^{6-8}$ Alum works by precipitating protein on the mucosal surface and by strengthening intercellular bridges. ${ }^{8}$ It is given by continuous bladder irrigation, is not absorbed, and has no systemic toxicity. The instillation is painless, does not damage the bladder mucosa, and controls bleeding effectively. Unfortunately, the same cannot be said of other agents which have been used for this distressing condition.

Five per cent to $10 \%$ formalin controls the bleeding in up to $80 \%$ of cases, ${ }^{910}$ but it is absorbed systemically and so may cause toxicity and it may also cause severe mucosal damage. At least one death has been reported. ${ }^{9}$ Formalin may also produce ureteric fibrosis as a result of the vesicoureteric reflux often present in patients with bladder disorders, but 